\title{
Personalized medicine and disruptive innovation: Implications for technology assessment
}

\author{
Kevin A. Schulman, $M D^{1,2,4}$, Ana Valverde Vidal, $M B A^{1,3}$, and D. Clay Ackerly, $M D^{1}$
}

\section{THE PROMISE OF PERSONALIZED MEDICINE}

New technologies offer the potential for revolutionary changes in the practice of medicine from molecular diagnostic tests that detect disease before symptoms are evident to patient profiling techniques that help predict which patients are most likely to benefit from or be harmed by specific therapies. These approaches and the extensive data they require will need to be supported by a new information architecture. This system has been described as personalized health care-treatments and services targeted to the biology of the individual, leading to potentially significant improvements in patient care. Although this vision has been articulated for several years, researchers are slowly gathering the information required to support the adoption of technologies that will be the crucial building blocks of the system. Other aspects of this vision are less developed, and the rationale for investment required to bring new technologies to market remain speculative.

At the policy level, there are recurring questions of the correct approach to innovation in health care. Do we have the right public policies and private strategies in place to foster innovation in the health care system? At the core of these discussions, there is a question of whether personalized health care will require a new approach to technology assessment and dissemination, one that embraces the tremendous potential of the vision of personalized medicine. What is the role of tech-

From the ${ }^{1}$ Duke Clinical Research Institute, Duke Translational Medicine Institute and Departments of ${ }^{2}$ Medicine and ${ }^{3}$ Community and Family Medicine, Duke University School of Medicine, Durham, North Carolina; and ${ }^{4}$ Health Sector Management Program, The Fuqua School of Business, Duke University, Durham, North Carolina.

Kevin A. Schulman, MD, Center for Clinical and Genetic Economics, Duke Clinical Research Institute, PO Box 17969, Durham, NC 27715. E-mail: kevin.schulman@duke.edu.

A previous draft of this paper was commissioned by the Initiative on Personalized Health Care, Office of the Assistant Secretary for Planning and Evaluation, US Department of Health and Human Services.

Disclosure: Dr Schulman reports receiving research support from Actelion Pharmaceuticals, Allergan, Amgen, Astellas Pharma, Bristol-Myers Squibb, The Duke Endowment, Genentech, Inspire Pharmaceuticals, Johnson \& Johnson, Kellogg Foundation, Kureha Corporation, LifeMasters Supported SelfCare, Medtronic, Merck \& Co, Nabi Biopharmaceuticals, National Patient Advocate Foundation, North Carolina Biotechnology Center, NovaCardia, Novartis, OSI Eyetech, Pfizer, Sanofi-Aventis, Scios, Tengion, Theravance, Thomson Healthcare, and Vertex Pharmaceuticals; receiving personal income for consulting from McKinsey \& Company and the National Pharmaceutical Council; having equity in Alnylam Pharmaceuticals; having equity in and serving on the board of directors of Cancer Consultants, Inc; and having equity in and serving on the executive board of Faculty Connection, LLC. Dr Schulman has made available online a detailed listing of financial disclosures (http://www.dcri.duke.edu/research/coi.jsp). No other disclosures were reported.

Submitted for publication March 25, 2009

Accepted for publication April 30, 2009.

Published online ahead of print July 14, 2009.

DOI: $10.1097 /$ GIM.0b013e3181ae0935 nology innovation in health care, and what should be the public policy responses to innovation?

\section{TECHNOLOGY AND INNOVATION IN HEALTH CARE}

Technology development and diffusion can offer new opportunities for patient benefit. In assessing the role of technology innovation, one field of scholarship has explored the relationship between technology innovation and organizational innovation. This line of inquiry presents a useful framework for discussions of the broader policy questions related to personalized medicine.

New technology often is accompanied by new business models. In competitive markets, innovation in technology enables new business models to use the advances of the new technology to offer cost or quality advantages to the end user. When successful, these new combinations of technology and business strategy are able to supersede their predecessors. ${ }^{1,2}$ This issue has been examined in detail by Christensen, ${ }^{3}$ who assessed the relationship between technology innovation and organizational innovation in the computer disk drive industry.

Christensen's concept of "disruptive innovation" begins with the assumption that consumer demand for a given technology is distributed normally, with the tails of the consumer preference curve representing high-end users with specific needs and price insensitivity and the low-end users with limited needs and price sensitivity. Firms already in the marketplace offer their products to all users but develop their technologies to meet the needs of the high-end users, their most valued customers. High-end users are thought to be the most profitable consumers and to be the most articulate about their needs. To satisfy the demands of this group, firms improve their technologies over time within the constraints of an existing business model, an approach Christensen termed "sustaining innovation." The resulting products and services target the needs of the most lucrative segments of the market.

Christensen's key observation is that so-called sustaining innovation leads firms to develop products that possess capabilities far beyond the needs of the average consumer. This strategy creates opportunities for new firms to enter the market with new technologies and business models that focus on the more limited needs of average consumers. When successful, these new firms can supplant the existing firms in a process called "disruptive innovation."

There are many examples of disruptive technologies. One is digital photography, which was eventually disruptive to photographic film photography. When introduced to the market, digital photography technology resulted in worse picture quality than traditional film photos so it met the needs of few users in the market. However, the convenience of digital photography allowed it to grab a market niche.

We then developed the concepts of computer storage and sharing and the market expanded. Eventually, as the camera technology improved and market share increased, digital pho- 
tography was able to surpass film photography and dominate the marketplace. Another example is the minicomputer, which was a disruptive innovation to the mainframe market; personal computers were in turn a disruptive innovation to the minicomputer market. Mobile telephones were disruptive to fixed-line telephones. This dynamic process of firm entry and firm exit from markets offers tremendous potential benefits to consumers over time in terms of reduced costs and improved quality.

\section{DISRUPTIVE INNOVATION IN HEALTH CARE?}

In the health sector, it is difficult to identify examples of truly disruptive technologies. Some have argued that home glucose monitoring, coronary angioplasty, and the nurse practitioner model are examples of disruptive innovations in health care. ${ }^{3}$ However, none of these technologies have been able to fully disrupt the market. None has fundamentally changed the system of primary care or fostered the development of new and innovative models of health care delivery. ${ }^{4}$ In most cases, these innovations have been unable to develop into the type of disruptive innovations we see in other markets when the new replaces the old. ${ }^{1,2}$ Instead, technology has generally added to existing systems in the manner of sustaining innovation. ${ }^{5}$ Physicians have fought the entry of the nurse practitioner model, and payment regulations restrict nurse practitioners to a primary care role. ${ }^{6}$ The business model to offer a real-time interface between home glucose monitoring and physician offices has taken years to evolve. ${ }^{4}$ Furthermore, angioplasty relies on the same hospital-based model as cardiac surgery; the procedure is simply performed by a cardiologist instead of a cardiac surgeon. 4

In short, there is a lack of solid examples of disruptive innovation in health care. It is not difficult to discern why this might be the case. The health care industry exists through a relationship between business and government that is different from the computer disk drive industry that Christensen observed. These interactions, in the form of regulations, professional standards, and administrative procedures, create opportunities for incumbents to support the status quo by erecting barriers to market entry. The typical firm bringing a disruptive innovation to market is unable to meet these established rules because it characteristically offers products or services with a narrower or more limited scope, a different business model, and potentially a different customer focus from that of incumbent firms. An unintended consequence of this system is an environment that supports sustaining innovation over disruptive innovation. The health care market does not have the advantage of disruptive innovation to drive cost and quality improvements in the marketplace.

\section{ADMINISTRATIVE BARRIERS TO INNOVATION}

Regulatory controls have the effect of developing a set of rules and standards for a market, including rules governing market expansion and process for firm entry into a market. Regulations in health care include the governance of third-party payments in health insurance, ${ }^{7}$ a medical liability system based on the standard of care, or rules on hospital markets (certificateof-need requirements). As discussed earlier, new entrants may not meet these administrative criteria or may not be able to navigate this process. As a result, all of these regulations may inhibit entry of new business forms.

Market entry is a dynamic process. Given an equal opportunity, entry will be greater when profit opportunity is greatest and barriers to entry are lowest. Given the high cost of most services in health care and the inherent profitability of the system, the health care market should be an attractive opportunity for firm entry. Also, given the quaternary care model rampant in the marketplace, existing firms have developed capacity that outstrips the needs of most consumers (and have failed to provide the front-end services demanded by most consumers). So the lack of entry should not be ascribed to a lack of interest in the market by investors.

There is a constraint on entry in this simple model - the cost of entry. The cost of entry can be seen as the cost of complying with administrative processes to create a new business model, or the cost of complying with regulatory standards that require entrants to achieve the same form or capabilities as incumbents to enter the market. These requirements can increase the cost of entry to the point where entry is no longer attractive to new firms. ${ }^{4}$ Alternatively, these factors may alter the risk of any investment by increasing uncertainty regarding approval of a new business model.

The relative lack of firm entry has consequences throughout the health care marketplace on both incumbents and new entrants. In the absence of new market entrants (or a viable threat of entrants), organizational innovation of existing firms lags or disappears (Richman BD, Mitchell W, Schulman KA, unpublished study). This lack of organizational innovation on the part of incumbent firms compounds the cost and quality consequences of firm trajectories comprised of sustaining innovation on the marketplace.

\section{THE POLICY MAKER'S ROLE}

This discussion has emphasized the potential negative consequence of current regulatory and governance practices on the health care marketplace. Clearly, regulations serve an essential role in the health care system. ${ }^{4}$ However, by establishing a threshold above average consumer performance expectations, regulations may also preclude quality-enhancing, lower-cost innovations from entering the market. What can policy makers do to promote innovation and allow new technologies to enter this regulated marketplace? Another way of framing this question is how should we take account of the negative externalities of a regulatory scheme on the marketplace?

One simplistic framework would suggest we should support adoption of disruptive innovations over sustaining innovations. This approach is clearly supported by the theoretical framework, but it contrasts with current technology adoption models in which most technologies that reach the market are simply sustaining innovations that "add on" to existing technologies. For example, greater availability of angioplasty is now associated with more revascularization procedures among elderly patients. ${ }^{8}$ Similarly, the availability of more magnetic resonance imaging units does not reduce the number of computed tomography scans performed. ${ }^{8}$

Supporting disruptive over sustaining innovations is not a simple task. Disruptive innovation is not a result of technology innovation; rather, it is a combination of business and technology innovations. It is unclear from an assessment of a technology itself whether the business model is one that offers the potential for disruption. Second, although many products purport to be disruptive innovations, true disruptive innovations can only be identified in arrears when markets have changed as a result of the innovations. Even with these limitations, however, potential pathways forward could emerge.

First, not all types of innovation are, or should be, of equal interest to policy makers. In most markets, sustaining innovations are those that enter the market continuously. New versions 
of Microsoft Windows and new models of the iPod come to market with greater capabilities than previous versions at equal or lower prices. From this perspective, the regulatory approach could be one that expects sustaining innovation as a condition of remaining in the marketplace and limits the financial rewards to products or services over time. For example, imagine if we lowered the price for a magnetic resonance imaging each year based on an index of computer costs in the broader marketplace.

The treatment of potentially disruptive innovations, however, could be considered quite differently. In health care, disruptive innovations face tremendous obstacles with new combinations of technology and business models that have not previously existed. Based on the concept presented to this point, regulators could consider facilitating entry of these firms and technologies as a means of enhancing the price and quality of health care services for consumers. At the same time, regulators should curtail these incentives for firms and products that do not prove to be disruptive. This suggests that broader regulatory reform would accomplish the former goal of allowing access but at the expense of many sustaining innovations benefiting from the new framework. An alternative would be a time-dependent facilitated pathway for market entry that is unique to the regulatory framework we have constructed for health care. For example, policy makers could determine a mechanism to identify technologies with the potential to become disruptive and to allow these technologies to enter the market in a disruptive fashion.

\section{EXPLORING POLICY OPTIONS}

One such mechanism would be the creation of an office of personalized medicine (OPM) charged with reviewing new technology applications to determine if they have the potential to become disruptive. With data and business cases presented by the owners of the technologies, the OPM would assess the ability of an innovation to transform health care delivery and treatment and eventually lead to improvements in both outcomes and costs. Such a review mechanism would encourage technology owners to think beyond the novel characteristics of their proposals to consider other important business and operational features that would eventually determine if an innovation goes beyond being sustaining to become truly disruptive.

For innovations deemed disruptive by the OPM, policy makers could play an important role in providing incentives for these technologies to successfully enter the market. Owners of disruptive innovations could receive vouchers for accelerated review, or the innovations could command a premium in reimbursement negotiations. Regulators could even define a special regulatory pathway for these technologies, with distinct market approval and reimbursement criteria that would more closely align with the characteristics of these technologies. As an alternative, regulators could carve out "safe harbors" for these technologies, giving the owners of such innovations flexibility and time to change the prevailing business models in their sector. After a model similar to "coverage with evidence development" at the Centers for Medicare and Medicaid Services (CMS), innovations considered disruptive could be subject to special reimbursement mechanisms for a given period, altering the prevailing incentive system in the market and enabling the new technology to take hold. For example, under the current encounter-based reimbursement system, health care providers have little incentive to acquire technologies that enhance service but reduce the number of clinic encounters, because such innovations would likely result in reduced revenues for the provider. Under a "safe harbor" mechanism, health care providers who use an OPM-labeled disruptive technology to remotely monitor patients would likely be able to bill for the informal communications that such technologies would generate (e.g., e-mail consultations and phone conversations).

\section{EXAMPLE: THE COMPLEX DEVELOPMENT PATH FOR A POTENTIALLY DISRUPTIVE INNOVATOR}

One clinical application for personalized medicine is targeted therapy for individual patients. ${ }^{9}$ The potential implication of this approach is to offer improved safety and efficacy for individual patients ${ }^{10}$ and have an immediate economic impact by avoiding therapies with low potential for efficacy (although one would expect manufacturers to respond to this technology in terms of development and pricing strategies over time).

Currently, the regulatory pathway for development of diagnostic tests for personalized medicine applications is controversial and depends on whether the test or the information from the test kit is the product. A company seeking approval for a novel molecular diagnostic test for which the test kit is being marketed requires approval from the Center for Devices and Radiologic Health (CDRH) at the Food and Drug Administration (FDA). ${ }^{11} \mathrm{CDRH}$ classifies devices into three regulatory classes based on the anticipated use of the technology and the inherent risk. The class assignment determines the requirements for approval and the complexity of the marketing approval process (i.e., either premarket notification or the more stringent and lengthy premarket approval).

Alternatively, in vitro diagnostic devices can be developed and marketed under the Clinical Laboratory Improvement Act (CLIA) of 1988, which governs "laboratory-developed tests" (i.e., tests performed in a single site where the test kit is not marketed; samples can come to the laboratory for this service from anywhere in the country). CLIA establishes three categories of testing on the basis of the complexity of the testing methodology: waived tests, tests of moderate complexity, and tests of high complexity. Laboratories performing moderate- or high-complexity testing must meet requirements for proficiency testing, patient test management, quality control, quality assurance, and personnel. However, CLIA-governed tests do not require FDA approval.

The distinction between these two separate pathways has created a special area of controversy for personalized medicine. Using gene expression technology, scientists have reported the ability to classify patients based on risk of disease recurrence. ${ }^{12}$ Although the technology is in its infancy, the FDA has raised concerns about the regulatory pathway for in vitro diagnostic multivariate index assays. These devices combine the values of multiple variables using an interpretation function to yield a single, patient-specific result that is intended for use in the diagnosis of disease or in the cure, treatment, or prevention of disease; and they provide a result with a nontransparent derivation that cannot be independently derived or verified by the end user. ${ }^{13}$

Most in vitro diagnostic multivariate index assays in the market are laboratory-developed tests marketed through the CLIA route, that is, tests developed by a single clinical laboratory for use in that laboratory alone. Given the strategy of not marketing the test kits and performing the tests at a single site, these tests did not fall within the scope of laboratory tests over which the FDA had generally exercised enforcement discretion. Concern over this space has led to a proposal to begin regulation of this market by the FDA, with the issuance by CDRH of draft guidance in July 2007.13 This regulatory issue has not yet been resolved. 
In addition to regulatory approval, companies seeking to enter the market with new molecular diagnostic tests also must work with CMS to obtain reimbursement for their products. This separation of approval and reimbursement results from the different missions assigned to both FDA (approval) and CMS (reimbursement). FDA approval is based on meeting statutorily defined criteria of safety and effectiveness, and literally provides permission to market a product in the United States. Implementation of these criteria varies by product category but serves as a minimum set of criteria for entry into a market. FDA review and approval are not an assessment of value or uniqueness, nor a recommendation for use or funding of a product or technology.

Conversely, CMS review is based on a statutorily defined standard of "reasonable and necessary" for the treatment of illness or injury. This standard for reimbursement is an assessment of whether a technology should be used in the care of Medicare beneficiaries. It is a relative standard and can be influenced by the existence of an unmet medical need, the existence of comparative therapies, and the value of a new technology. In principle, the separation of approval and reimbursement provides an easier entry to the market for a technology (approval) and allows the sale of a product even if there is no CMS reimbursement for the technology.

The CMS reimbursement process itself is complex. The process governs three key issues - coverage, coding, and payment. ${ }^{14}$ As mentioned earlier, to be covered by Medicare under the Social Security Act, the new technology must be "reasonable and necessary" for the treatment of illness or injury; however, technologies that are predictive may not meet this standard because prevention is not considered as a medical treatment. Second, as medical claims processing has become automated, assignment of specific codes for new medical technologies has taken on a unique importance in the reimbursement process. If specific codes are not available for a new technology, payment for the technology cannot be differentiated from existing technologies. Finally, payment schemes in Medicare can vary from bundles (inpatient diagnosis-related group payment) to specific (outpatient laboratory testing). When the technology will be reimbursed separately, a payment rate must be established.

Coverage, coding, and payment decisions are not necessarily made in a particular order, and the decisions can span a 12month period. To add to the complexity, different components of CMS are responsible for different aspects of these decisions. The Office of Clinical Standards and Quality oversees national quality initiatives and includes the Coverage and Analysis Group and its three divisions, which are responsible for developing national coverage policy. Payment and coding decisions are developed by the Center for Medicare Management, with two groups and 10 divisions potentially involved in the process. In addition, there is the possibility that different regional decisions can be made about these issues in the absence of a national decision.

In recent years, CMS has shown an awareness of the need to streamline this process and has taken several steps aimed at improving it. In 2004, the Council on Technology and Innovation (CTI) was established under the Medicare Prescription Drug, Improvement, and Modernization Act to serve as a coordination point for new medical technologies. In August 2008, the CTI published the Innovators' Guide to Navigating CMS ${ }^{14}$ to assist stakeholders in understanding the processes used to determine coverage, coding, and payment. Although serving to help technology developers understand the CMS process, the CTI group is not an expedited pathway to market for new technologies.
CMS has launched several demonstration projects to test innovations in reimbursement policy. For example, the coverage with evidence development policy provides an abbreviated pathway to Medicare coverage while still requiring further evaluation of a new technology. At the same time, CMS is working to make coding processes more efficient and has implemented a number of initiatives to reform one of its major coding systems, the Healthcare Common Procedure Coding System, while moving to replace the International Classification of Diseases, Ninth Revision, with the more flexible and clinically relevant Tenth Revision. ${ }^{15}$

\section{A WAY FORWARD FOR DISRUPTIVE INNOVATIONS}

Although these actions are steps in the right direction, a broader approach could help accelerate the access of disruptive innovations to the market. The OPM could play a significant role as a unifying and coordinating agency, acting as the single point of contact through the Department of Health and Human Services for technologies deemed disruptive. The OPM would expedite the approval process by expertly understanding all the potential pathways involved and helping the technology navigate the regulatory mesh. In this role, the OPM would act as an ombudsman for disruptive innovations that are seeking market approval. As described earlier, this process would not be open to all potential innovations but rather to those that, based on the technology characteristics and the proposed business model to implement them, are considered to have disruptive potential.

The consideration of disruptive potential would only be granted for a fixed period. If after such period the technology fails to deliver its disruptive promise and its novel business model fails to take hold, the OPM could elect to levy penalties on the company, either monetary (to repay the competitive advantage gained through early market entry) or other penalties (such as closing the OPM pathway for future innovations from the company for a given period). The intent is to make the penalty significant enough that companies will exercise best efforts to deliver on the disruptive promise of their innovations.

The OPM could build on these changes and work in tandem with the CTI, as well as the CMS Office of Research, Development, and Information. Close communication between these groups would ensure tight coordination through the regulatory and reimbursement approval processes. The OPM could also work with these groups to expand current initiatives and create new, larger demonstration projects or safe harbors for disruptive innovations. The OPM would also have to follow a strict timeline to ensure a speedy decision about whether a technology will meet the OPM standard.

Much of this policy assessment has focused on the unique role of the federal government in the health care marketplace. Private health plans often adopt much of their coding infrastructure from Medicare and can elect to follow Medicare in coverage decisions. Thus, efforts to adopt these policies by the public sector will have effects on the private sector, as well. Creating transparency in the rationale for OPM decisions and communicating the results of evaluation of technology implementation can also help to shape decisions in the private sector. The role of the private sector in fostering disruptive innovation merits further consideration.

\section{CONCLUSIONS}

Personalized medicine offers the potential for revolutionary change in the practice of medicine. It also provides a unique 
window into the relationship between new medical technologies, new business models for health care delivery, and role of government in this unique marketplace. Using personalized medicine as a test of disruptive innovation in health care, we find the need for a different approach to these technologies in order for them to achieve their full potential. Achieving this result, however, is fraught with difficulty, as disruptive innovations are deemed truly disruptive only in hindsight. Thus, our approach offers the potential that designations of a technology as potentially disruptive would provide competitive advantages to products or services that may not merit this consideration. A robust framework for continuing assessment (and the potential for penalties on misrepresented technologies) might help protect the integrity of this process. However, the benefits of unlocking the health care market to disruptive innovation seem to be worth the risk.

\section{REFERENCES}

1. Shumpeter JA. The theory of economic development. Cambridge: Harvard University Press, 1934.

2. Macher J, Richman B. Organisational responses to discontinuous innovation: a case study approach. Int J Innovat Manag 2004;8:87-113.

3. Christensen CM. The innovator's dilemma. Boston: Harvard Business School Press, 1997.

4. Curtis LH, Schulman KA. Overregulation of health care: musings on disruptive innovation theory. Law Contemp Probl 2006;69:195-206.
5. Eisenberg JM, Schwartz JS, McCaslin FC, Kaufman R, Glick H, Kroch E. Substituting diagnostic services. New tests only partially replace older ones. JAMA 1989;262:1196-1200.

6. Cooper RA, Henderson T, Dietrich CL. Roles of nonphysician clinicians as autonomous providers of patient care. JAMA 1998;280:795-802.

7. Berenson RA. A physician's view of managed care. Health Aff (Millwood) 1991;10:106-119.

8. Bodenheimer T. High and rising health care costs. Part 2: technologic innovation. Ann Intern Med 2005;142:932-937.

9. Ginsburg GS, Konstance RP, Allsbrook JS, Schulman KA. Implications of pharmacogenomics for drug development and clinical practice. Arch Intern Med 2005;165:2331-2336.

10. Roses AD. Pharmacogenetics and the practice of medicine. Nature 2000; 405:857-865.

11. Center for Devices and Radiological Health, Food and Drug Administration. Getting to market with a medical device. Available at: http://www.fda.gov/ cdrh/devadvice/3122.html. Accessed September 2, 2008.

12. Potti A, Mukherjee S, Petersen R, et al. A genomic strategy to refine prognosis in early-stage non-small-cell lung cancer. N Engl J Med 2006; 355:570-580.

13. Food and Drug Administration. Draft guidance for industry, clinical laboratories, and FDA staff: in vitro diagnostic multivariate index assays. Available at: http://www.fda.gov/cdrh/oivd/guidance/1610.pdf. Accessed September 2, 2008

14. Centers for Medicare and Medicaid Services. Innovators' guide to navigating CMS. Available at: http://www.cms.hhs.gov/CouncilonTechInnov/ Downloads/InnovatorsGuide8_25_08.pdf. Accessed September 2, 2008.

15. Council on Technology and Innovation, Centers for Medicare and Medicaid Services. Available at: http://www.cms.hhs.gov/CouncilonTechInnov/. Accessed September 2, 2008.

\section{Erratum}

Application of dual-genome oligonucleotide array-based comparative genomic hybridization to the molecular diagnosis of mitochondrial DNA deletion and depletion syndromes: Erratum

In the article that appeared on page 518 of volume11, issue 7, the disclosure statement was incomplete. The disclosure statement should have included the following: The Department of Molecular and Human Genetics at Baylor College of Medicine offers microarray testing service on a fee basis. This error has been noted in the online version of the article, which is available at www.geneticsinmedicine.org.

\section{REFERENCE}

Chinault AC, Shaw CA, Brundage EK, Tang L-Y, Wong, L-JC. Application of dual-genome oligonucleotide array-based comparative genomic hybridization to the molecular diagnosis of mitochondrial DNA deletion and depletion syndromes. Genet Med 2009;11:518-526. 